Document downloaded from:

http://hdl.handle.net/10251/31953

This paper must be cited as:

Gómez-tejedor, JA.; Rico Tortosa, PM.; Gómez Ribelles, JL.; Van Overberghe, N. (2011). Assessment of parameters influencing fiber characteristics of electrospun Poly(ethyl methacrylate) scaffolds. EUROPEAN POLYMER JOURNAL. 47(2):119-129. doi:10.1016/j.eurpolymj.2010.10.034.

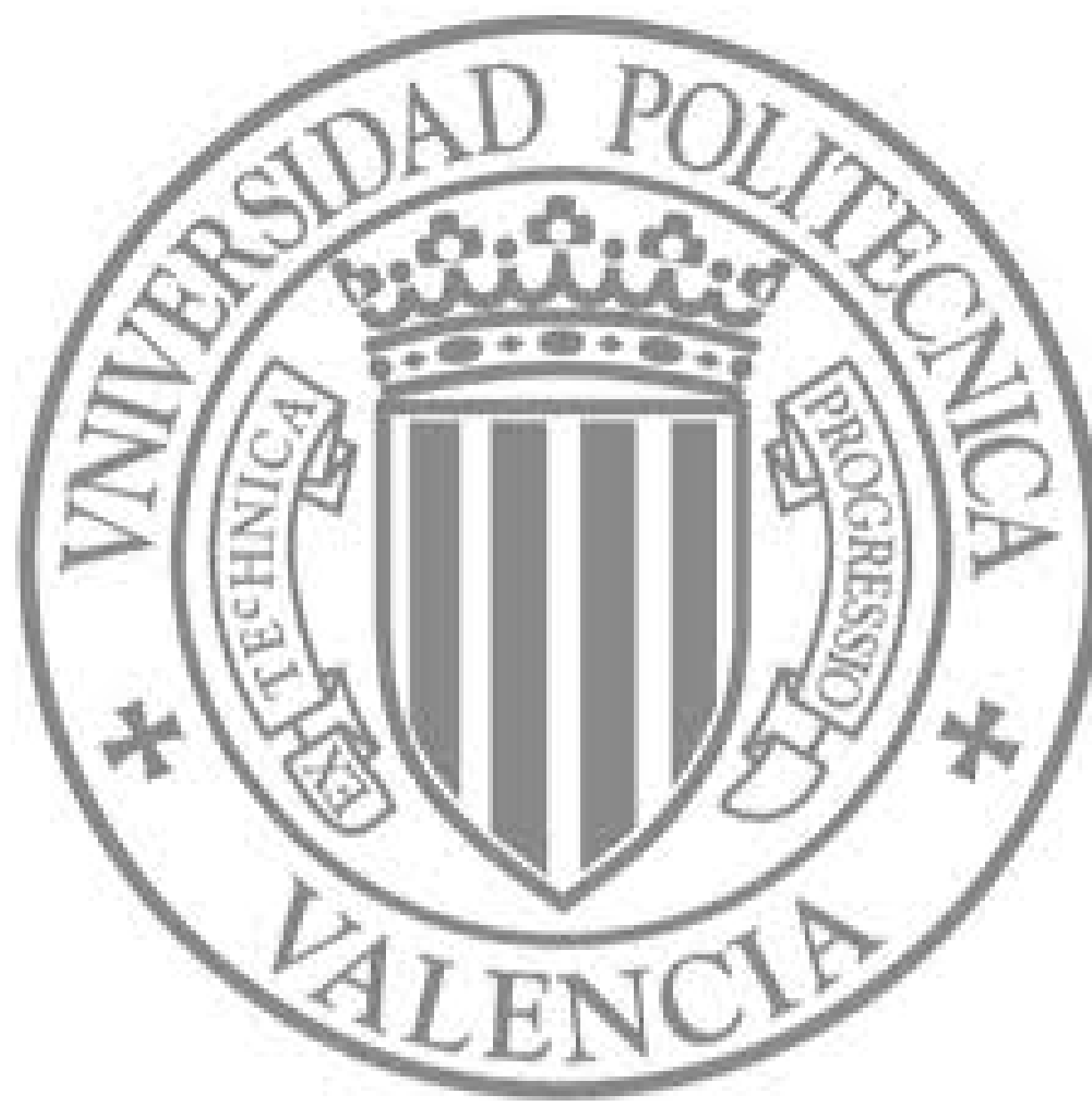

The final publication is available at

http://dx.doi.org/10.1016/j.eurpolymj.2010.10.034

Copyright Elsevier 


\section{Assessment of the parameters}

\section{influencing the fibre characteristics of \\ electrospun poly(ethyl methacrylate) membranes}

José Antonio Gómez-Tejedor, ${ }^{a^{*}}$ Niek Van Overberghe, ${ }^{a}$ Patricia Rico Tortosa, ${ }^{a}$ José Luís Gómez Ribelles s,b,c $^{\mathrm{a}}$

${ }^{a}$ Centro de Biomateriales e Ingeniería Tisular, Universidad Politécnica de Valencia. C.P.I.

Edificio 8E. Acceso F. Nivel 1. Camino de Vera s/n. E-46022 Valencia, Spain.

${ }^{\mathrm{b}}$ Regenerative Medicine Unit, Prince Felipe Research Centre, Valencia, Spain.

${ }^{\circ}$ CIBER en Bioingeniería, Biomateriales y Nanomedicina, Valencia, Spain.

"Corresponding author. Tel: +34 963 877276; Fax: +34 963877276.

Email: jogomez@fis.upv.es (J.A. Gómez Tejedor). 


\section{Abstract}

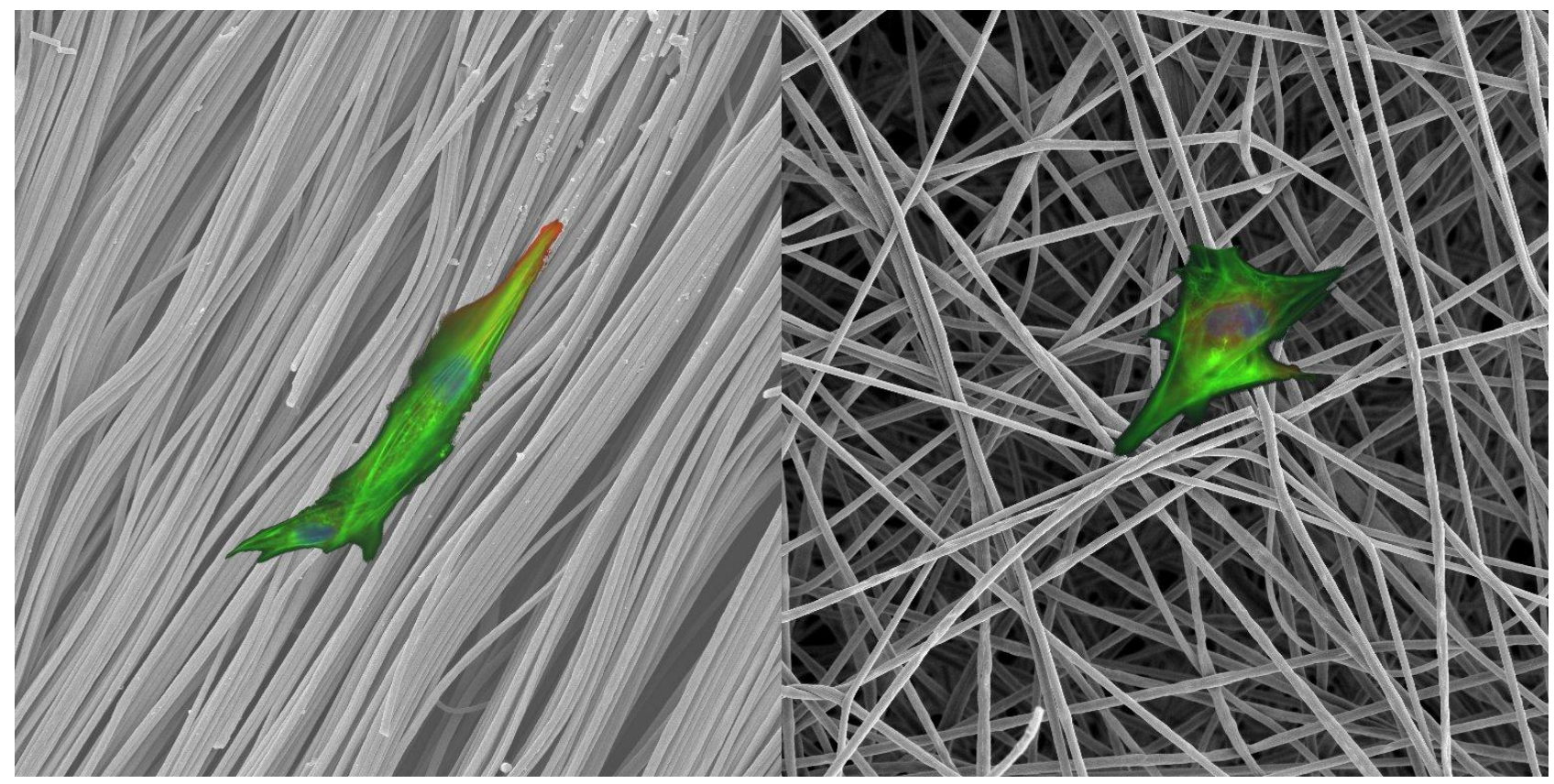

This work evaluates the influence of electrospinning process parameters on the mean diameter and standard deviation of fibre diameters in electrospun poly(ethyl methacrylate) or PEMA. Processing conditions were selected using Taguchi's statistical method. Oriented and unoriented electrospun mats with good mechanical properties were produced and demonstrated with tensile stress-strain diagrams. Differential scanning calorimetry (DSC) experiments showed that the polymer chains were forced into nonequilibrium conformations due to electrospinning. Enthalpic recovery during a heating scan is shown by an endothermic peak in the initial DSC heating scan that disappears in subsequent heating scans. An increase in the glass transition temperature with respect to PEMA films shows that the polymer is not equilibrated by heating above glass transition levels. Cell attachment was tested with MC3T3-E1 osteoblastic cells cultured for short time periods on the electrospun mats. It is shown that the cells present less extended morphology with more diffuse perimetral focal adhesions than cells cultured on flat substrates. A tendency of cells to align in the direction of the substrate fibres in oriented electrospun membranes was also found. 
Keywords: scaffold, cell growth, electrospinning, PEMA

\section{Introduction}

Among the various methods proposed to produce nanofibres and nanofibre mats (including drawing, phase separation, self-assembly, wet spinning, and others) electrospinning has been shown to be sufficiently versatile to be applied to nearly any soluble polymeric material. As a result, a large number of industrial applications have been found. A solution of polymeric material in a suitable solvent is projected from a metallic needle to an electrically conductive collector by a strong electrical field applied with a direct current high-voltage power supply (in the order of up to $30 \mathrm{kV}$ ). The action of the electrical field forms a jet that travels between the needle and the collector. This action causes the evaporation (at least partially) of the solvent and so precipitates submicron or nano-fibres on the surface of the collector. In the case of a static flat collector, the accumulation of electrospun fibres produces a mat of randomly oriented fibrils, whereas a high-speed rotating collector can orient the fibrils in the direction of the surface displacement [1-5].

One of the applications for electrospun mats is to act as supports or vehicles for cell culture, or cell implantation, in tissue engineering strategies. In these techniques, the regeneration of a damaged tissue or organ is induced by transplanting differentiated or pluripotential cells to the site of the damage in order to produce and organize an extracellular matrix for regenerating functional tissue. It has been shown that to achieve this effect most of the cells need a substrate, a scaffold, to attach themselves before 
JA Gómez-Tejedor et al., European Polymer Journal 47 (2011) 119-129

proliferating and differentiating to acquire the correct phenotype. Cellular adhesion to the substrate is mediated by extracellular matrix proteins that adsorb on the synthetic material. Once specific ligands of these proteins are recognized by the transmembrane cell proteins (the integrins) a cascade of events takes place in the cell cytoplasm and nucleus that addresses cell behaviour, morphology, phenotype, and proliferative and migrating abilities. In this aspect, the microstructure of the substrate plays an important role. In fact, the in vitro and in vivo biological response to a given material in the form of a flat substrate differs substantially from the response to the same material when in the form of a nanofibril mat. An explanation may be found in the similarity of the synthetic fibres to natural extracellular matrix components [6-9]. The number of research works dedicated to the study of potential of electrospun membranes, or scaffolds, in the engineering of living tissues is continuously increasing (see references [1,3,4,10-16] and the references therein).

In this work, we deal with poly(ethyl methacrylate) PEMA. Due to their proven biocompatibility and in vivo stability, PEMA polymers have been extensively used in ophthalmology implants and devices, bone cements, and in other applications such as permanent implants. Electrospun mathacrylate materials are used for engineering various tissues when a biostable support for cell transport is necessary; as in the case of stem cell transport in wound dressing systems; or in the biointegrable part of a permanent prosthesis (mainly as the anchoring ring of a cornea prosthesis, but also as cement fixation elements for bone prostheses). The biological response may strongly depend on fibril morphology and orientation. The goal of this paper is to evaluate which parameters have the greatest influence on fibre thickness and size distribution in electrospun PEMA fibres, and the biological response to electrospun PEMA mats is tested using the MC3T3E1 osteoblast-like cell line. 
The number of parameters that influence the morphology or homogeneity of electrospun fibrils is important: some of these parameters relate to the solution properties (viscosity, polymer concentration, polymer molecular weight, dielectric constant of the solvent, and conductivity). Other parameters relate to the electrospinning process itself (needle diameter, feed rate, electrical voltage applied, travelling distance between the needle and the collector, humidity, temperature, relaxation properties of the polymer, and chain orientation abilities due to jet straining); while another group of parameters relates to the collection (solvent volatility, alignment conditions, collector morphology, and porosity). The role of each parameter in the process and the way in which it affects fibril morphology is not well understood and contradictory results are frequently obtained when a single parameter is changed while keeping the others unchanged [2,11]. The obvious reason is that the development of electrospun fibres following a change in a given parameter can strongly depend on the values selected for the other parameters.

To reduce the number of experiments, a statistical method, Taguchi's orthogonal array [1720], was used with five parameters (polymer concentration, needle-to-collector distance, flow, needle diameter) with each having three possible values. A commercially available polymer PEMA was used for this method. The prepared samples were analyzed by scanning electron microscopy (SEM). Results showed that concentration and electrical field have the greatest influence on fibre thickness. The mechanical and thermal properties of the membranes were characterized.

\section{Materials and methods}

\section{Preparation of polymer solution}


PEMA with average molecular weight $\mathrm{M}_{\mathrm{w}}=350,000 \mathrm{Da}$ and produced by Polysciences, Inc, (Warrington, PA, USA) was dissolved in a mixture of methylene chloride and dimethyl formamide, DMF, containing 60 wt\% of the former to obtain solutions with a polymer concentration of $10,12.5$ and $15 \mathrm{wt} \%$.

\section{Taguchi's orthogonal design}

Five relevant parameters were investigated: polymer concentration in the solution, electrical field, electrode-collector travelling distance, flow rate, and needle diameter. Three possible values (three levels) for each parameter were tested. In a full factorial design of experiments with these parameters there would be $3^{5}=243$ combinations of parameters to test. Taguchi's orthogonal design was used [17-20] to reduce the number of experiments. For this number of parameters the orthogonal table $L 18$ was used [19-21], and so it was possible to evaluate parameter influence with only 18 experiments and these are shown in Table 1.

\begin{tabular}{|c|c|c|c|c|c|c|c|}
\hline Exp. & Concentration & field & distance & rate & diameter & $\bar{x}$ & $\sigma$ \\
No. & $(\mathrm{wt} \%)$ & $(\mathrm{kV} / \mathrm{cm})$ & $(\mathrm{cm})$ & $(\mathrm{ml} / \mathrm{h})$ & $(\mathrm{mm})$ & $(\mu \mathrm{m})$ & $(\mu \mathrm{m})$ \\
\hline $\mathbf{1}$ & 10 & 1 & 10 & 5 & 0.3 & 1.37 & 0.20 \\
\hline $\mathbf{2}$ & 10 & 1.25 & 15 & 3 & 0.4 & 1.6 & 0.3 \\
\hline $\mathbf{3}$ & 10 & 1.5 & 20 & 4 & 0.5 & 1.2 & 0.4 \\
\hline $\mathbf{4}$ & 12.5 & 1 & 10 & 3 & 0.4 & 2.9 & 0.8 \\
\hline
\end{tabular}


JA Gómez-Tejedor et al., European Polymer Journal 47 (2011) 119-129

\begin{tabular}{|c|c|c|c|c|c|c|c|}
\hline 5 & 12.5 & 1.25 & 15 & 4 & 0.5 & 3.6 & 1.9 \\
\hline 6 & 12.5 & 1.5 & 20 & 5 & 0.3 & 2.3 & 1.2 \\
\hline 7 & 15 & 1 & 15 & 5 & 0.5 & 3.1 & 1.1 \\
\hline 8 & 15 & 1.25 & 20 & 3 & 0.3 & 3.3 & 2.5 \\
\hline 9 & 15 & 1.5 & 10 & $\overline{4}$ & 0.4 & 2.1 & 0.6 \\
\hline 10 & 10 & 1 & 20 & 4 & 0.4 & 2.2 & 0.3 \\
\hline 11 & 10 & 1.25 & 10 & 5 & 0.5 & 2.4 & 0.4 \\
\hline 12 & 10 & 1.5 & 15 & 3 & 0.3 & 1.5 & 0.3 \\
\hline 13 & 12.5 & 1 & 15 & 4 & 0.3 & 2.4 & 0.8 \\
\hline 14 & 12.5 & 1.25 & 20 & 5 & 0.4 & 2.5 & 1.0 \\
\hline 15 & 12.5 & 1.5 & 10 & 3 & 0.5 & 3.4 & 1.5 \\
\hline 16 & 15 & 1 & 20 & 3 & 0.5 & 3.5 & 0.8 \\
\hline 17 & 15 & 1.25 & 10 & 4 & 0.3 & 6 & 4 \\
\hline 18 & 15 & 1.5 & 15 & 5 & 0.4 & 2.3 & 0.8 \\
\hline
\end{tabular}

Table 1. Design of orthogonal table L18 and mean value $(\bar{x})$ and standard deviation $(\sigma)$ of the diameter of obtained fibres.

\section{Electrospinning}

We used a vertical setup for the electrospinning material with $0.3,0.4$, or $0.5 \mathrm{~mm}$ medical syringes. The flow of the NE-1600 syringe pump (New Era Pump Systems, Wantagh, NY, USA) was set at $0.3 \mathrm{ml} / \mathrm{h}, 0.4 \mathrm{ml} / \mathrm{h}$ or $0.5 \mathrm{ml} / \mathrm{h}$. A high voltage power supply (Glassman High Voltage, NJ, USA) produced electrical fields of $1,1.25$ or $1.5 \mathrm{kV} / \mathrm{cm}$. The fibres were collected on a flat aluminium foil situated at 10, 15, or $20 \mathrm{~cm}$ from the needle (see Table 1). To produce aligned fibres, a spindle covered with aluminium foil and mounted on a variable-speed motor was used. The rotation speeds were set at 1200,2500 , or 3800 rpm; meaning a linear speed of $450 \mathrm{~m} / \mathrm{s}, 940 \mathrm{~m} / \mathrm{s}$, and $1430 \mathrm{~m} / \mathrm{s}$ respectively. 


\section{Fibre diameter characterization}

The electrospun fibres were characterized by a scanning electron microscope (SEM) JEOL JSM 6300 (JEOL Ltd, Tokyo, Japan) at $10 \mathrm{kV}$ and Image image analyzing software [22]. The fibre diameters and segment lengths were measured from multiple SEM images, and 100 fibres were analyzed per experiment. The mean diameter and standard deviation were calculated using the expressions

$$
\begin{gathered}
\bar{x}=\frac{1}{L_{t o t}} \sum L_{i} x_{i} \\
\sigma=\sqrt{\frac{\sum \mathbf{C}_{i} \triangleleft_{i}-\bar{x}^{叉}}{L_{t o t}}}
\end{gathered}
$$

where $L_{t o t}=\sum L_{i}$ and $L_{i}$ is the length of the fibre segment diameters $x_{i}$. For each fibre segment, the average of three measurements taken at different points was used.

\section{Degree of alignment}

The degree of alignment was obtained by analyzing the SEM images of aligned fibres with ImageJ software and the Oval Profile (Bill O'Connell [23]) external plug-in. Firstly, images were cropped to a size of $768 \times 768$ pixels. A fast Fourier transformation (FFT) was then applied to these images, rendering an image with pixel intensities. Images were then rotated $90^{\circ}$ counter-clockwise to correct for the $90^{\circ}$ rotation that is inherent in this analysis. Oval Profile was then used to sum the pixel intensities along a circle for each one-degree sector, resulting in a graph of pixel intensities across $360^{\circ}$. For further evaluation only $180^{\circ}$ were necessary due to the mirroring properties of the graph. The FFT data was normalized to a baseline value of 0 and plotted in arbitrary units ranging from 0 to 1 [24-27].

\section{Mechanical properties}


JA Gómez-Tejedor et al., European Polymer Journal 47 (2011) 119-129

Mechanical experiments were performed on Seiko EXSTAR 6000 equipment using the extension mode. Our samples were rectangular cross-sections: the aligned sample dimensions were approximately $16 \times 5 \times 0.02 \mathrm{~mm}$; while the non-aligned samples measured $21 \times 7 \times 0.8 \mathrm{~mm}$. Non-aligned samples were much thicker since they are much more fragile.

The sample elongation was measured as a function of applied tension, and measurements were performed until the samples broke. The stress-strain curves were drawn from this experimental data, and a linear fit of the initial curve was used to estimate Young's modulus of samples.

\section{DSC}

Differential scanning calorimetry was performed with a PerkinElmer Pyris 1. A dry nitrogen flow of $20 \mathrm{ml} / \mathrm{min}$ was used to enhance heat transfer. The weight of the measured samples ranged between 2 and $6 \mathrm{mg}$. Before measurements, samples were kept in a vacuum at $30^{\circ} \mathrm{C}$ for seven days to evaporate the remains of the solvent employed in electrospinning. An initial scan was made from $20^{\circ} \mathrm{C}$ to $100^{\circ} \mathrm{C}$ at a heating rate of $10^{\circ} \mathrm{C} / \mathrm{min}$. The sample was then immediately cooled to $20^{\circ} \mathrm{C}$ at $20^{\circ} \mathrm{C} / \mathrm{min}$ and a second heating scan at $10^{\circ} \mathrm{C} / \mathrm{min}$ was performed.

\section{Cell culture}

MC3T3-E1 cells were obtained from the Riken Cell Bank (Japan). Prior to seeding on fibronectine-coated substrates, the cells were maintained in a DMEM medium supplemented with $10 \%$ foetal bovine serum and $1 \%$ penicillin-streptomycin; and passaged twice a week using standard techniques. Sample disks (12 mm diameter) placed on a 24-well tissue culture plate were coated with $\mathrm{FN} 20 \mathrm{mg} / \mathrm{ml}\left(12 \mathrm{~h}\right.$ at $\left.37^{\circ} \mathrm{C}\right)$. Some 
JA Gómez-Tejedor et al., European Polymer Journal 47 (2011) 119-129

10000 cells were then placed on each substrate and maintained at $37^{\circ} \mathrm{C}$ in a humidified atmosphere with $5 \% \mathrm{CO}_{2}$ for $3 \mathrm{~h}$. Each experiment was performed in triplicate.

\section{Cell adhesion}

After 3h of culture MC3T3-E1 cells were washed in Dulbecco's phosphate buffered saline (DPBS, Invitrogen) and fixed in $10 \%$ formalin solution (Sigma) at $4 \stackrel{\circ}{ } \mathrm{C}$ for $1 \mathrm{~h}$. The samples were then rinsed with DPBS and a permeabilising buffer $(10.3 \mathrm{~g}$ sucrose, $0.292 \mathrm{~g} \mathrm{NaCl}$, $0.06 \mathrm{~g} \mathrm{MgCl}$, $0.476 \mathrm{~g}$ Hepes buffer, $0.5 \mathrm{ml}$ Triton $\mathrm{X}$, in $100 \mathrm{ml}$ water, $\mathrm{pH}$ 7.2) was added at room temperature for $5 \mathrm{~min}$. To reduce the background signal, the samples were then incubated in $2 \%$ BSA/DPBS at room temperature with the primary antibody anti-vinculin (SIGMA, dilution 1:400) for 1h. The samples were then incubated with a secondary antibody anti-mouse (dilution 1:20000) and with BODIPY® FL phallacidin (2-3 units/sample, molecular probes). The samples were then rinsed in DPBS three times for 5 min each. Finally, samples were washed before being mounted in Vectashield containing DAPI staining (Vector Laboratories). A Leica DM6000B fluorescent microscope was used. The image system was equipped with a Leica DFC350FX camera.

\section{Results and discussion}

\section{Fibre diameter and morphology}

Table 1 shows the mean diameter and standard deviation, SD, of the obtained electrospun fibres. Fibres with a wide range of diameters from 1.25 to $5.8 \mu \mathrm{m}$ can be obtained through different parameter selections. It should be noticed than in some cases, the standard deviation of the fibre diameter is very large (see, for instance, experiments $5,8,15$, and 17), and this means that in these cases we obtained very inhomogeneous fibres. In other 
cases, the standard deviation was much smaller (see, for instance, experiments 1, 2, 10, and 12) and we obtained very homogeneous electrospun fibres. This is illustrated in Figure 1, where SEM images for various cases are shown. The formation of secondary jets may produce a broad distribution of fibre diameters [28-30]. It has been reported that a narrow distribution of fibre diameters is favoured by an increase in the viscosity of the solution and a decrease in surface tension [31, 32].

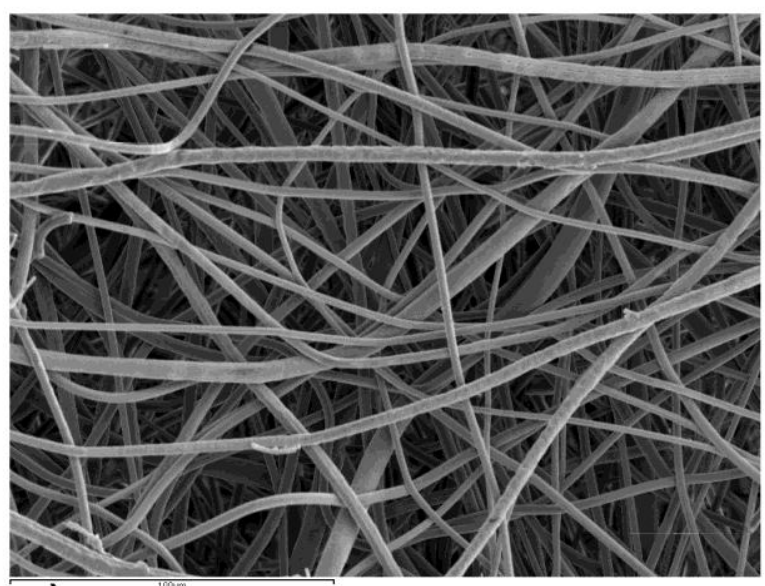

a)

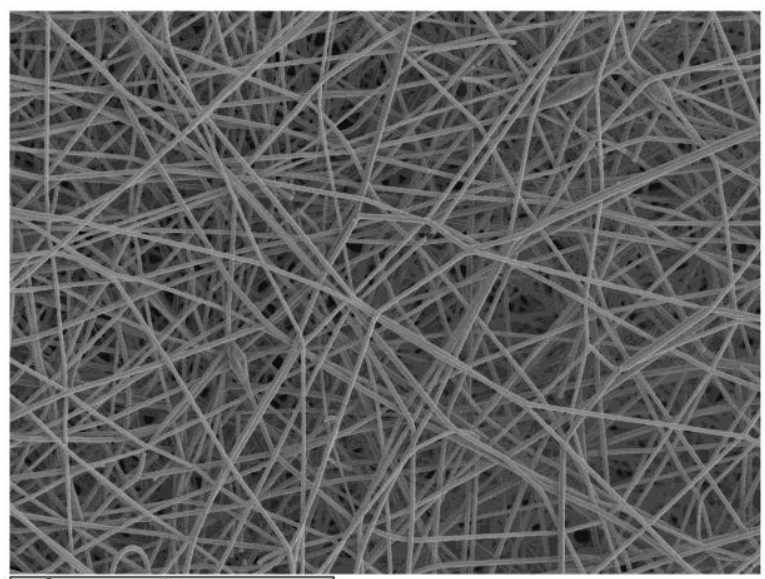

C)

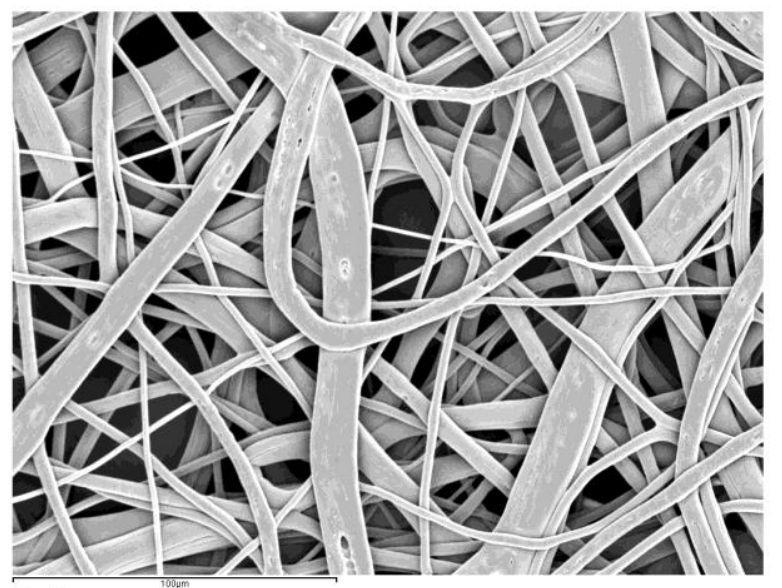

b)

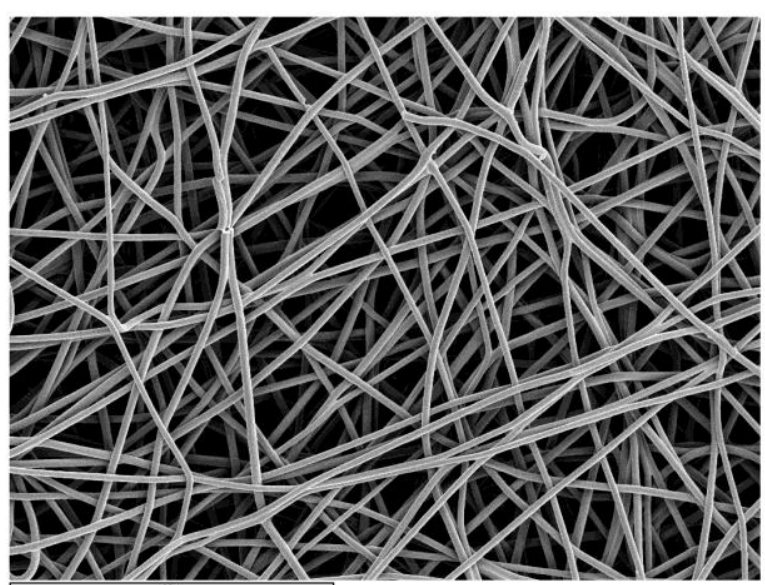

d)

Figure 1. SEM image of random electrospun fibres: a) Experiment 5: 12.5 wt\% PEMA, $1.25 \mathrm{kV} / \mathrm{cm}, 15 \mathrm{~cm}, 4 \mathrm{ml} / \mathrm{h}$ and $0.5 \mathrm{~mm}$ needle diameter. Fibre diameter: $3.6 \pm 1.9 \mu \mathrm{m} . \mathrm{b})$ experiment 17: $15 \mathrm{wt} \%$ PEMA, 1,25 kV/cm, $10 \mathrm{~cm}, 4 \mathrm{ml} / \mathrm{h}$ and $0.3 \mathrm{~mm}$ needle diameter. Fibre diameter: $6 \pm 4 \mu \mathrm{m}$. c) Experiment 1: $10 \mathrm{wt} \%$ PEMA, $1 \mathrm{kV} / \mathrm{cm}, 10 \mathrm{~cm}, 5 \mathrm{ml} / \mathrm{h}$ and 
JA Gómez-Tejedor et al., European Polymer Journal 47 (2011) 119-129

0.3mm needle diameter. Fibre diameter: $1.37 \pm 0.20 \mu \mathrm{m} . \mathrm{d})$ Experiment 10: $10 \mathrm{wt} \%$ PEMA, $1 \mathrm{kV} / \mathrm{cm}, 20 \mathrm{~cm}, 4 \mathrm{ml} / \mathrm{h}$ and 0,4 mm needle diameter. Fibre diameter: $2.2 \pm 0.3 \mu \mathrm{m}$. In all images, bar scale is $100 \mu \mathrm{m}$.

The signal-to-noise ratio, or the SN number, needs to be calculated for each experiment to measure the effect each variable has on output [19]:

$$
S N_{j}=10 \log \left(\frac{\bar{x}_{j}^{2}}{\sigma_{j}^{2}}\right)
$$

Where $\bar{x}^{2}$ is the mean diameter and $\sigma_{j}$ is the standard deviation of experiment number $j$.

The calculated mean effects of different levels of each parameter on the signal-to-noise ratio, fibre diameter, and the $S D$ of the diameter are shown in Table 2 . The range in the table is the difference between the maximum and minimum values of the three levels, and the importance of the parameter is obtained by the range: the parameter with the largest range being the most important.

\begin{tabular}{|l|l|c|c|c|c|c|}
\hline & & Concentration & Electric field & Distance & Flow velocity & Nozzle \\
diameter
\end{tabular}


JA Gómez-Tejedor et al., European Polymer Journal 47 (2011) 119-129

\begin{tabular}{|c|c|c|c|c|c|c|}
\hline \multirow{5}{*}{$\begin{array}{c}\text { Fibre } \\
\text { diameter } \\
\bar{x}(\mu \mathrm{m})\end{array}$} & Level 2 & 2.9 & 3.2 & 2.43 & 2.91 & 2.28 \\
\hline & Level 3 & 3.4 & 2.1 & 2.52 & 2.34 & 2.89 \\
\hline & Range & 1.7 & 1.1 & 0.58 & 0.57 & 0.62 \\
\hline & Importance & 1 & 2 & 4 & 3 & 5 \\
\hline & Best level & $10 \mathrm{wt} \%$ & $1.5 \mathrm{kV} / \mathrm{cm}$ & $15 \mathrm{~cm}$ & $5 \mathrm{ml} / \mathrm{h}$ & $0.4 \mathrm{~mm}$ \\
\hline \multirow{6}{*}{$\begin{array}{l}\text { Standard } \\
\text { deviation } \\
\sigma(\mu \mathrm{m})\end{array}$} & Level 1 & 0.3 & 0.6 & 1.3 & 1.0 & 1.5 \\
\hline & Level 2 & 1.2 & 1.7 & 0.9 & 1.3 & 0.6 \\
\hline & Level 3 & 1.6 & 0.8 & 1.0 & 0.8 & 1.0 \\
\hline & Range & 1.3 & 1.1 & 0.4 & 0.5 & 0.9 \\
\hline & Importance & 1 & 2 & 5 & 4 & 3 \\
\hline & Best level & 10 wt $\%$ & $1 \mathrm{kV} / \mathrm{cm}$ & $15 \mathrm{~cm}$ & $5 \mathrm{ml} / \mathrm{h}$ & $0.4 \mathrm{~mm}$ \\
\hline
\end{tabular}

Table 2. Mean effects of various levels of each parameter on the SN ratio, fibre diameter and its SD. The importance of the parameter is determined by the range (difference between the maximum and minimum) of each parameter (largest range being the most important). The best level leading to the smallest diameters and the narrowest diameter distributions was also selected.

None of the sets of parameters selected yielded sub-micron electrospun fibres. From these results, we observe that concentration and electrical field have the largest influence on fibre characteristics. The effect of the concentration of the solution is quite clear: electrospinning a solution with the lowest concentration ( $10 \%$ by weight) yields the thinnest fibres and with uniform diameters. This result is achieved nearly independently of the remaining parameters, and in particular, independently of the voltage applied. Table 2 shows the average value of $1.7 \mu \mathrm{m}$ recorded in all the sets of parameters tested with a concentration of $10 \mathrm{wt} \%$. As shown in Table 2, the average standard deviation in the 
JA Gómez-Tejedor et al., European Polymer Journal 47 (2011) 119-129

experiments with 10 wt\% solutions is also the smallest. Figures 1c and 1d are representative examples of these types of electrospun samples. On the contrary, the effect of the applied electrical fields is unclear and is very dependent on the remaining parameters. For instance, when examining experiments 1 to 3 and 10 to 12 with the 10 wt\% solution it seems that electrical field has little influence on the fibre diameter and standard deviation; nevertheless, in the particular conditions of experiment 17 , the fibres are significantly larger than under the other conditions. The effect of the electrical field on the fibre diameter is unclear in the literature, while in several cases a decrease in the fibre diameter with increasing applied voltages has been reported [30,33-35]. In other cases, no significant or not monotonous change has been found $[32,36]$. This may be due to the fact that changes in the applied voltage also affect other parameters in the process; such as the travelling time of the jet, which in turn, affects fibre diameter - possibly in the opposite direction to the voltage itself. The effect of the electrical field can therefore depend on the values of the other process parameters. This explains why the average fibre diameter found by averaging the results recorded in the set of experiments performed with a given voltage value is likely to change substantially - but not monotonously - with the value of the voltage. No systematic dependence of the standard deviation on the applied voltage was found, and extremely high values for intermediate electrical fields were recorded in experiments 8 and 17 . The effect of the other parameters is generally smaller that that of concentration and electrical field, and as happens with electrical fields, the dependence is not systematic.

In the next step, we choose $10 \mathrm{wt} \%$ for the solution concentration and $1 \mathrm{kV} / \mathrm{cm}$ for the electrical field as the optimal values. These values were chosen because they have the higher signal-to-noise ratio, and at the same time, the lowest standard deviation. Other parameters have less influence on fibre characteristics. We chose a feeding rate of $5 \mathrm{ml} / \mathrm{h}$ 
JA Gómez-Tejedor et al., European Polymer Journal 47 (2011) 119-129

because it is the best choice for the SN ratio, fibre diameter, and SD. We chose $10 \mathrm{~cm}$ for the needle-collector distance because this value has a higher signal-to-noise ratio, and produces a more homogeneous film scaffold. We chose a needle diameter of $0.3 \mathrm{~mm}$ because other parameter values produce needle obstructions and so make it more difficult to obtain a homogeneous film scaffold. This choice of parameters matches experiment number 1 , where the fibre diameter obtained is $1.37 \mu \mathrm{m}$ with a standard deviation of 0.20 $\mu \mathrm{m}$ (see Figure 1c).

\section{Aligned fibres}

We used a rotating collector under the same conditions to prepare electrospun aligned fibres. By varying the motor speed to three different values $(1200,2500$, and $3800 \mathrm{rpm})$, scaffolds with different degrees of alignment were obtained and compared with a randomly collected sample. 
JA Gómez-Tejedor et al., European Polymer Journal 47 (2011) 119-129

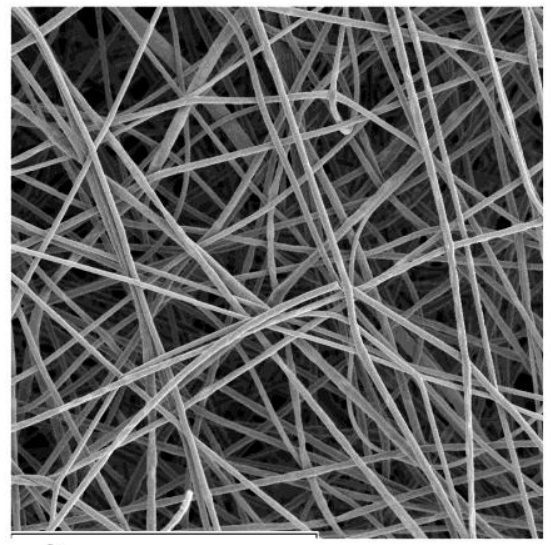

a)

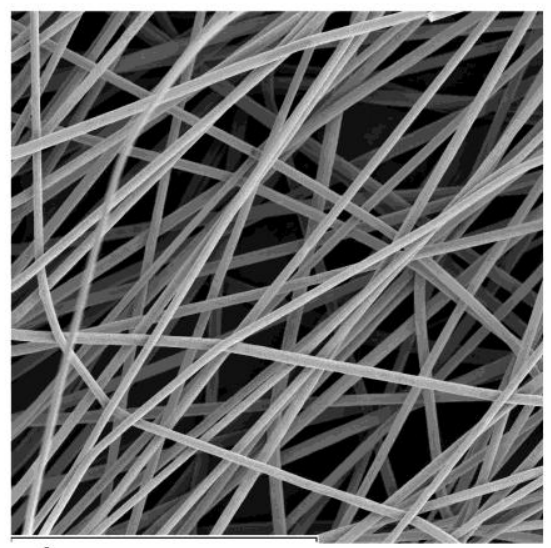

C)

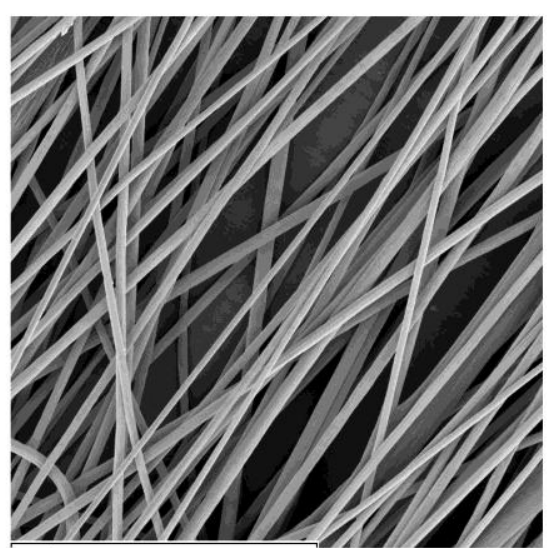

e)

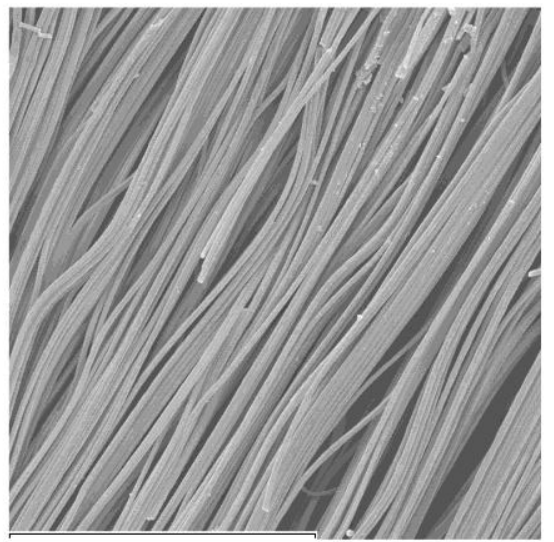

g)

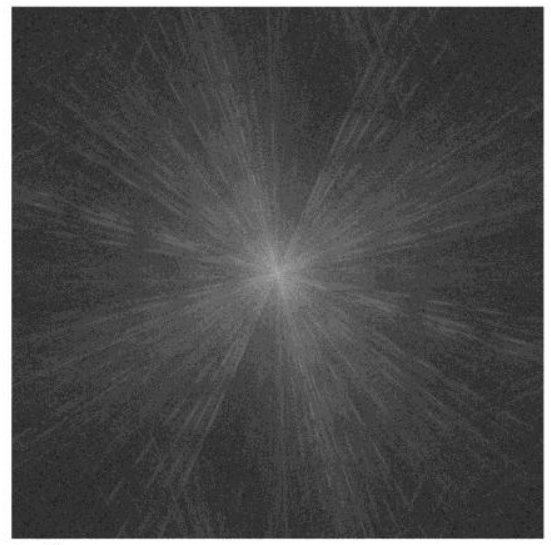

b)

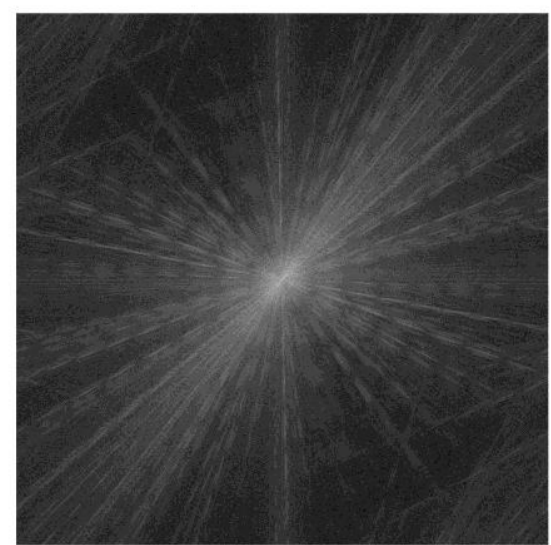

d)

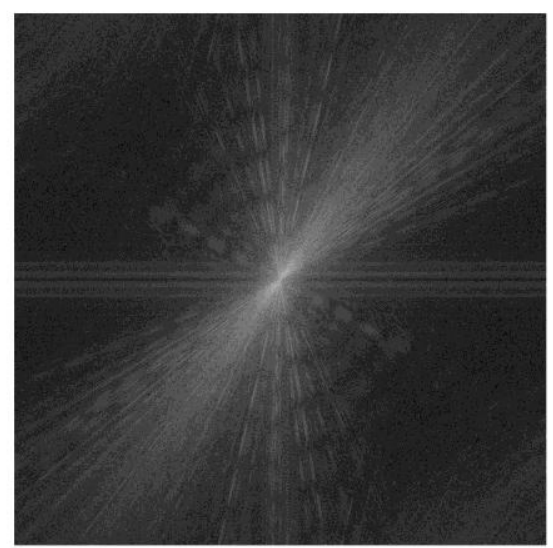

f)

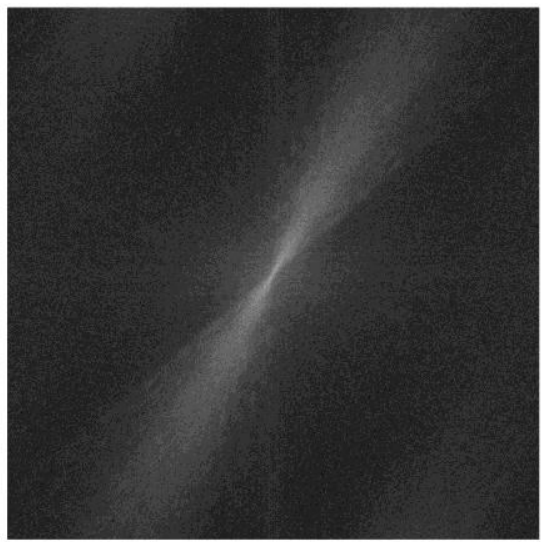

h) 
Figure 2: a) SEM image of random electrospun fibres. c), e) and g) SEM images of aligned electrospun fibres obtained with a rotating collector with motor speed 1200, 2500 and 3800 rpm respectively. b), d) f) and h) FFT of the left SEM images. In all cases, electrospinning conditions are: $10 \mathrm{wt} \%$ PEMA, $1 \mathrm{kV} / \mathrm{cm}, 10 \mathrm{~cm}, 5 \mathrm{ml} / \mathrm{h}$ and $0.3 \mathrm{~mm}$ needle diameter. Bar scale is $100 \square \mathrm{m}$.

In Figures $2 \mathrm{a}$ ) to $2 \mathrm{~g}$ ), we can see how the fibres become more aligned as rotation speed increases.

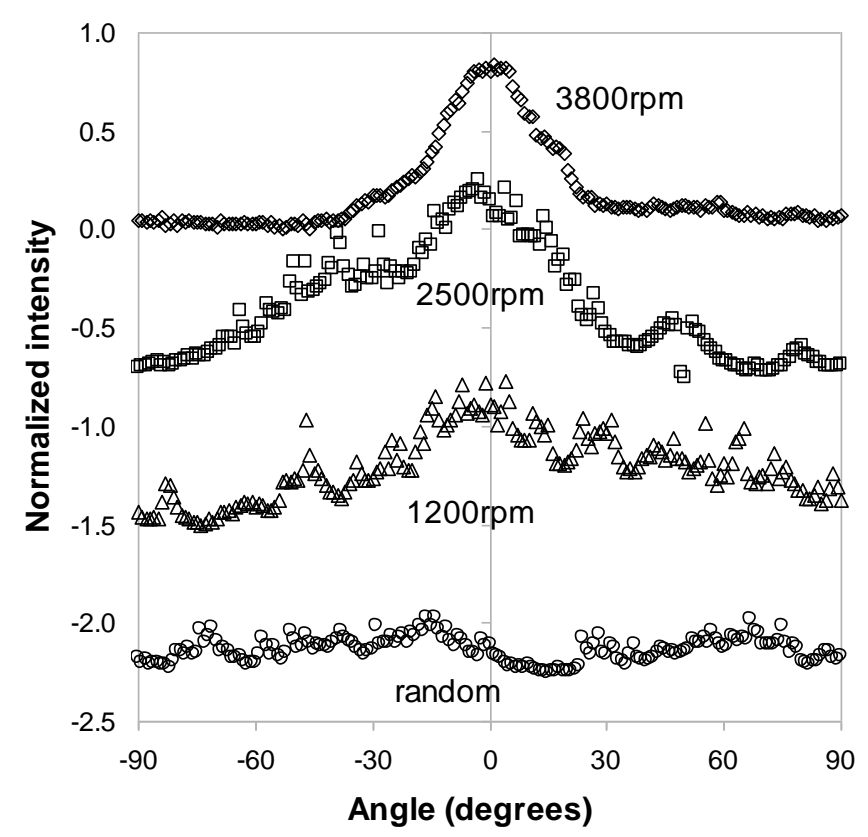

Figure 3: Graph of normalized summed radial intensities of FFT for the three motor velocities and random PEMA electrospun fibers. Ordinate scale corresponds to the collector rotation speed of $3800 \mathrm{rpm}$, the other curves have been shifted by $0.75 \mathrm{U}$ with respect to the precedent for clarity. 
JA Gómez-Tejedor et al., European Polymer Journal 47 (2011) 119-129

For a better comparison, in Figure 3 we have plotted the normalized intensity for the four studied cases. As expected, normalized intensity at maximum speed has the narrowest distribution. At lower speeds, the normal intensity distribution broadens. The graph with randomly aligned fibres does not show any preferred orientation.

\section{DSC}

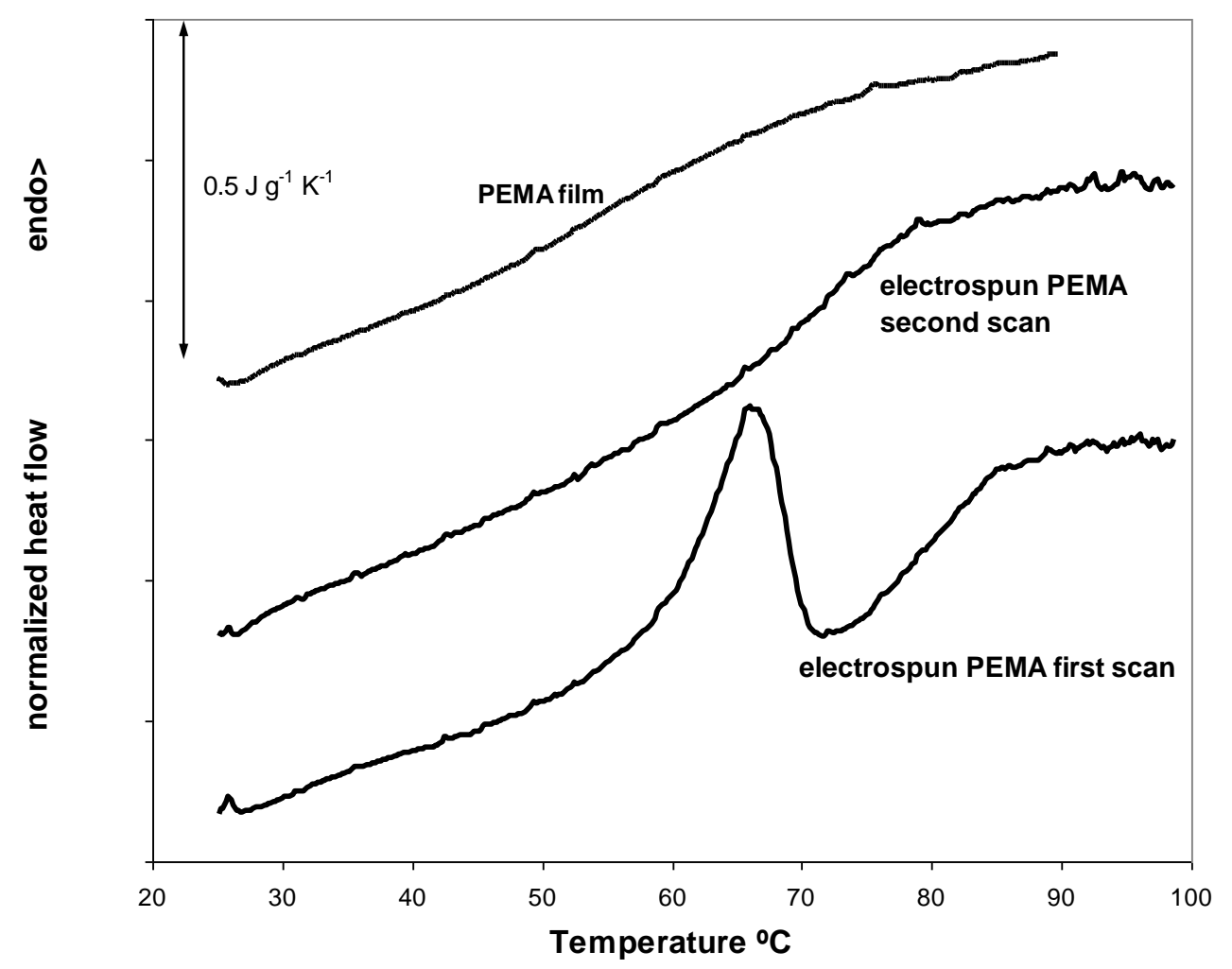

Figure 4. DSC thermograms of first and second heating thermograms of aligned electrospun fibers prepared with the conditions of experiment 1 in Table 1. The results are compared with those obtained in PEMA film.

DSC thermograms of electrospun samples show clear differences with respect to PEMA film. Figure 4 shows that the heating thermogram corresponding to PEMA film presents a 
JA Gómez-Tejedor et al., European Polymer Journal 47 (2011) 119-129

broad glass transition covering a temperature interval of more than 30 degrees, as usual in polymethacrylate polymers. The first heating scan performed on electrospun samples shows an endothermic peak just before the glass transition, a phenomenon analogous to that observed in amorphous samples subjected to physical ageing during annealing in the glassy state at a temperature below the glass transition. During physical ageing, polymer chains in the non-equilibrium glass pack closely together while decreasing specific volume and enthalpy, and approach the equilibrium state corresponding to the annealing temperature. When heating past the glass transition, a rapid approach of the enthalpy to equilibrium values originates a peak in heat capacity. In our samples, it seems that polymer chains are forced into non-equilibrium configurations during electrospinning. During the DSC heating scan, the chains reorganize and search for free energy minimization as they acquire sufficient mobility; and this produces an increase in the enthalpy in a short temperature interval that is manifested by an endothermic peak in heat flow in the DSC trends. It was not possible to correlate the shape or position of the peak with electrospinning process parameters - although the phenomenon appeared in all the tested samples (Figure 4 shows a representative case). After the first scan, the electrospun sample was cooled and reheated. The thermogram recorded in the second scan shows a normal heat flow step which is shifted towards higher temperatures with respect to PEMA film and also narrows. Again it is difficult to correlate the glass transition temperature of the electrospun samples with processing parameters. DSC sample pans were opened after the experiments and samples observed by SEM showed no significant change in fibre morphology due to thermal treatment. The shift towards higher temperatures (in some cases more than 20 degrees, as shown in Figure 4), indicates a decrease of chain mobility in electrospun fibres - and this may be related to chain orientation in the amorphous state. Other authors have reported a decrease in the glass transition temperature in electrospun fibres with respect to films, a fact that was ascribed 
JA Gómez-Tejedor et al., European Polymer Journal 47 (2011) 119-129

to confinement or surface phenomena [1]. However, this type of feature probably does not have a significant effect in our samples since the PEMA fibrils are not thin enough.

\section{Mechanical properties}

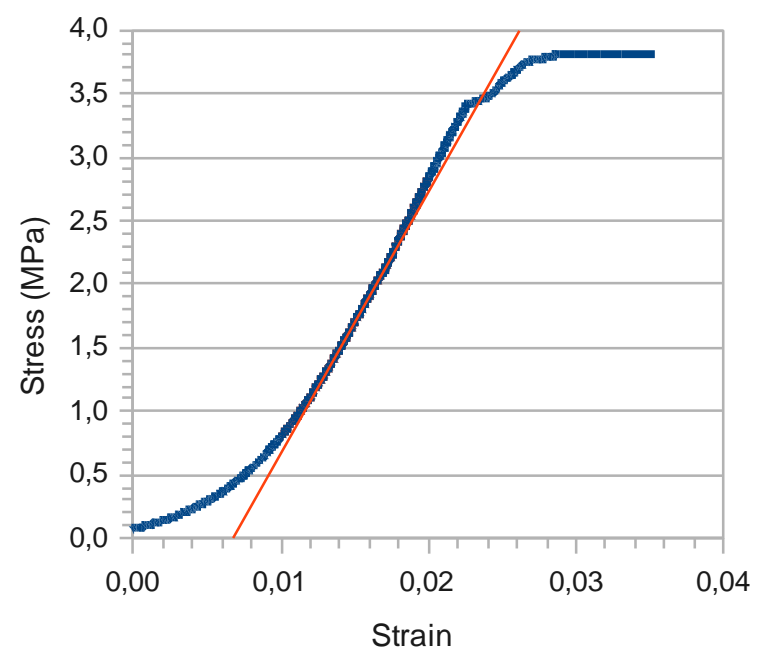

(a)

Figure 5: Stress-strain curve of aligned (a)

(b)

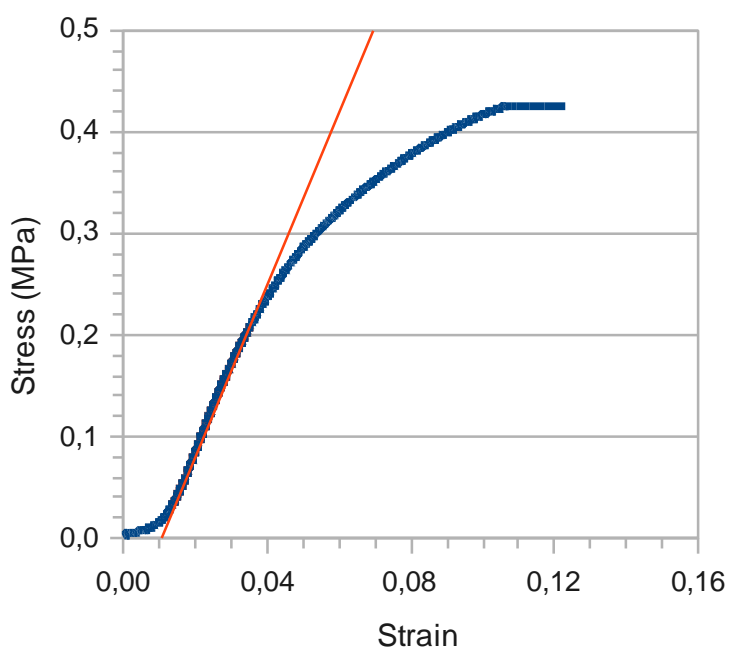

Strain lines: linear fit for Young modulus calculation.

Stress-strain experiments were performed in electrospun mats made of aligned and nonaligned fibres. Both mats are flexible and mechanically consistent. The stress-strain experiments were performed at room temperature, and thus fibres in the glassy state are shown in Figure 5. The absolute values of the stress applied must be considered with care since the cross-sections of the samples have been calculated from external dimensions and the porosity of the material and orientation of the fibres can vary significantly under electrospinning conditions - as explained above.

Fibre orientation during the experiments on non-aligned mats enabled greater stress to be applied - starting with small values. This involved taking the sample out of the linear 
JA Gómez-Tejedor et al., European Polymer Journal 47 (2011) 119-129

elastic regime at very low deformations or even at the beginning of the test. The stressstrain diagram of the aligned electrospun PEMA corresponds to an elastic polymeric material in which the fracture takes place immediately after yield. In general terms, the stress at break is then several times higher in aligned than non-aligned mats; while the apparent Young modulus calculated from the slope of the linear region of the curve is 200 $\mathrm{MPa}$ for aligned fibres and 8.5 MPa for random fibres. These results agree with those found in other aligned electrospun materials [37,38].

\section{Osteoblastic MC3T3-E1 cell culture}

The influence of the characteristic surface topography of electrospun mats on cell attachment has been evaluated in short-term osteoblastic MC3T3-E1 cell culture. Cell binding to the substrate surface is mediated by proteins that are adsorbed on the polymeric substrate $[39,40]$. In our experiments fibronectin was previously adsorbed on PEMA surfaces. Fibronectin is a well known protein involved in the adhesion of skeletical tissue cells to extracellular matrices. Cells were cultured without serum in order to avoid adsorption of other proteins from the serum in competition with fibronectine previously adsorbed on the substrate. Specific protein domains in fibronectin are recognized by the external part of the integrin receptor $\alpha 5-\beta 1$ pair [40]. These pairs cluster and attract a number of cytoplasmatic proteins such as vinculin, tensin, and others, to form focal adhesions where polymerization of actin fibrils is initiated. Actin cytoskeleton is crucial in many cellular processes including survival, migration, proliferation, and differentiation $[41,42]$. Development of focal adhesions and F-actin cytoskeleton of cells cultured on aligned or non-aligned electrospun mats was compared with those cultured on flat PEMA supports. 

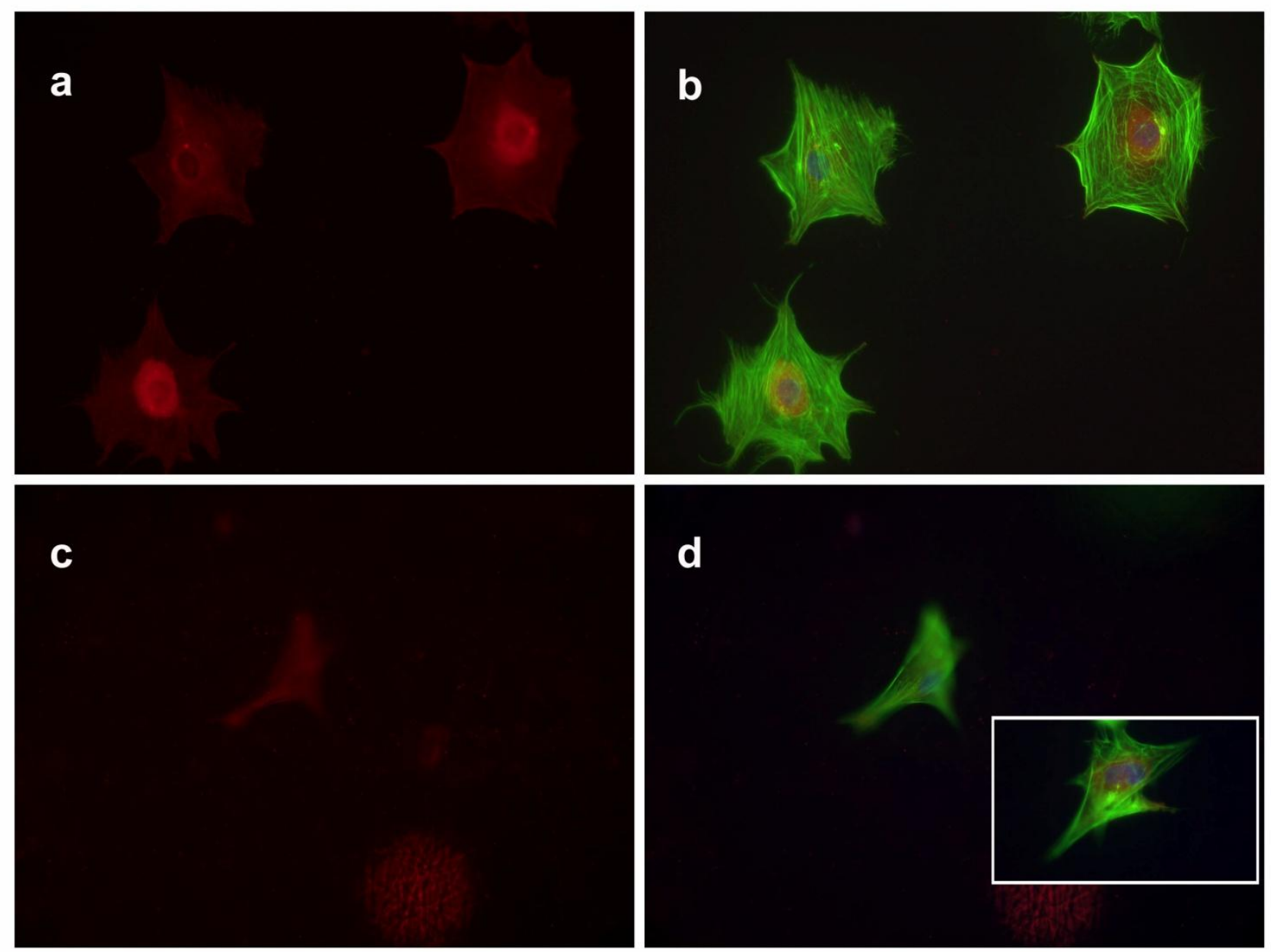

e

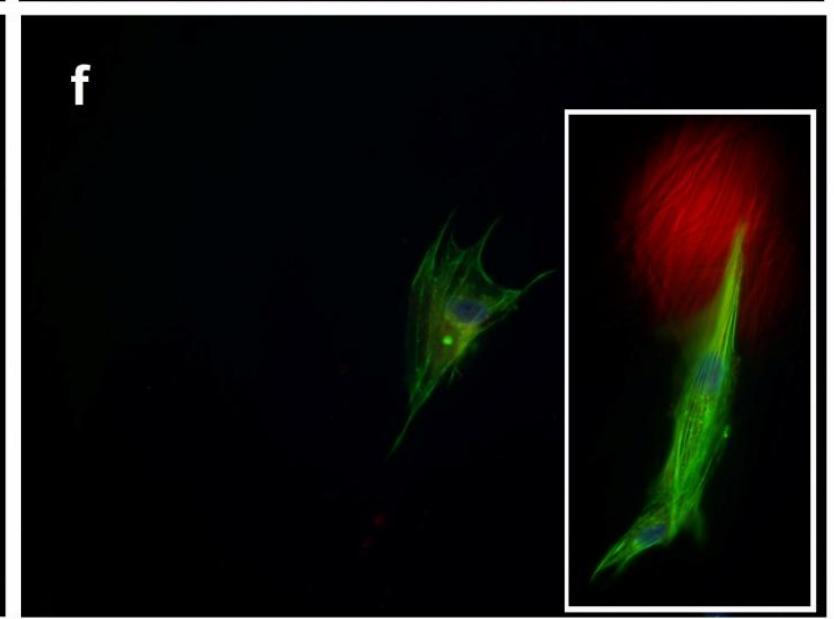

Figure 6: FM-images of MC3T3-E1 pre-osteoblastic cells attachment to PEMA supports. (a) and (b) show cells cultured on flat substrates; (c) and (d) show unoriented electrospun membranes; and (e) and (f) show oriented electrospun mats. (a), (c) and (e) show inmunoflurescence images using anti-vinculin antibodies to prove focal adhesions. In panels (b), (d) and (f) a vinculin image is superposed with F-actin staining (green) while cell nuclei are counterstained in blue. Insets in pictures (d) and (f) show other examples of 
JA Gómez-Tejedor et al., European Polymer Journal 47 (2011) 119-129

cells cultured in unoriented, and oriented mats, respectively. Red spots in pictures (c) and the inset of figure ( $f$ ) show the dimensions and orientation of electrospun fibrils for comparison with cells. (For interpretation of the references in color in this figure legend, the reader is referred to the web version of this article.)

Figure 6a shows fluorescence microscopy image of MC3T3-E1 cells cultured for three hours on flat PEMA and which were immunodetected with conjugated fluorescent antivinculin antibodies. Internal and perimetral focal adhesions are clearly shown. Cells present extended polygonal morphology with well defined contours. Perimetral focal adhesions colocalize with the ends of the F-actin fibres that densely fill the cytoplasms (Figure 6b), and cell nuclei are counterstained with Dapi. Cells cultured on non-oriented electrospun substrates are less spread, more irregular than on flat substrates, and have smaller surfaces. As Figure $6 \mathrm{c}$ shows, perimetral focal adhesions and cell contours are not well defined. A micro-drop of secondary antibody was used to enhance the staining of PEMA substrate and randomly oriented fibrils can be observed. This observation enables a comparison to be made of the dimensions of the cells and those of the substrate fibres. Figure 6d shows high density F-actin staining; however, cell contours are not clearly defined in this picture. The inset in this figure shows (at the same magnification) another example of cells cultured on a non-oriented electrospun mat.

Cells cultured on oriented fibres tend to orient themselves in the direction of substrate fibres, as shown in the inset in Figure 6f where the substrate has been non-specifically stained in red and the orientation of the electrospun fibres can be seen. Focal adhesions and the F-actin skeleton show the same characteristics as in unoriented mats. Cell 
JA Gómez-Tejedor et al., European Polymer Journal 47 (2011) 119-129

alignment in the direction of oriented grooves, channels, or fibres, is unsurprising and has been found in several cell culture types [43-45].

\section{Conclusions}

Electrospun poly(ethyl methacrylate) mats were obtained from solutions of the polymer in dimethyl formamide. A study of the influence of processing parameters on the fibre morphology shows that polymer concentration in the original solution has the greatest influence on fibre thickness; while electrical field has the largest influence on standard deviation. In all cases, fibres with diameters greater than one micron were obtained. Fibres were easily oriented using a high-speed rotating collector, and mats formed by aligned fibres present an apparent elastic modulus of around $200 \mathrm{MPa}$ at room temperature. Fibre formation during the electrospinning process forces the packing together of polymer chains as detected by endothermal peaks in the thermograms obtained when heating beyond the glass transition. Even after thermal treatment above $\mathrm{T}_{g}$, the glass transition of the electrospun fibres is significantly higher than in PEMA film. Nevertheless, no correlation between the glass transition behaviour of the samples and processing parameters was found. Cell attachment was tested with MC3T3-E1 osteoblastic cultured cells during short time periods on the electrospun mats. It is shown that cells present less extended morphology with more diffuse perimetral focal adhesions than cells cultured on flat substrates. A tendency of cells to align in the direction of substrate fibres in oriented electrospun membranes was also found. 
JA Gómez-Tejedor et al., European Polymer Journal 47 (2011) 119-129

\section{Acknowledgements}

The support of the Spanish Ministry of Science through projects MAT2007-66759-C03-01, including European Regional Development Fund financial support, with complementary funding from the Valencian regional government under project ACOMP/2009/112 and the Universidad Politécnica de Valencia under project 2911-2008 is acknowledged.

José Antonio Gómez Tejedor acknowledges the support given by the regional government of Valencia, the Generalitat Valenciana, under project GVPRE/2008/160.

José Luís Gómez Ribelles acknowledge funding from the Prince Felipe Research Centre in the field of regenerative medicine through a cooperative agreement with the Conselleria de Sanidad (Valencian regional government), and the Instituto de Salud Carlos III (Spanish Ministry of Science and Innovation).

The language revision of this paper was funded by the Universidad Politécnica de Valencia, Spain. 
JA Gómez-Tejedor et al., European Polymer Journal 47 (2011) 119-129

\section{References}

1. Zong $\mathrm{XH}$, Kim K, Fang DF, et al. Structure and process relationship of electrospun bioabsorbable nanofibre membranes. Polymer 2002;43:4403-4412.

2. Ramakrishna S, Fujihara K, Teo WE, Lim TC, Ma Z. An Introduction to Electrospinning and Nanofibres. World Scientific, Singapore, 2005.

3. Boudriot U, Dersch R, Greiner A, Wendorff JH. Electrospinning Approaches Toward Scaffold Engineering—A Brief Overview. Artif Organs 2006;30(10):785-792.

4. Sill TJ, Recum HA. Electrospinning: Applications in drug delivery and tissue engineering. Biomaterials 2008;29:1989-2006.

5. Xie J, Li X, Xia Y. Putting Electrospun Nanofibres to Work for Biomedical Research. Macromol. Rapid Commun. 2008;29:1775-1792.

6. Ikada Y. Challenges in tissue engineering. J. R. Soc. Interface 2006;3:589-601.

7. Langer R, Vacanti JP. Tissue engineering. Science 1993;260:920-926.

8. Patrick CW, Mikos AG, Mclntire LV. Prospects of tissue engineering. In: Patrick, CW, Mikos, AG, Mclntire, LV, eds. Frontiers in Tissue Engineering. Oxford: Elsevier Science Ltd, 1998:3-11.

9. Koh CJ, Atala A. Tissue engineering, stem cells, and cloning. Opportunities for regenerative medicine. J Am Soc Nephrol , 2004;15(5):1113-1125. 
10. Agarwal S, Wendorff JH, Greiner A. Use of electrospinning technique for biomedical applications. Polymer 2008;49:5603-5621.

11. Reneker DH, Yarin AL. Electrospinning jets and polymer nanofibres. Polymer 2008;49:2387-2425.

12. Theron SA, Zussman E, Yarin AL. Experimental investigation of the governing parameters in the electrospinning of polymer solutions. Polymer 2004;45:2017-2030.

13. Ishii $Y$, Sakai $H$, Murata $H$. A new electrospinning method to control the number and diameter of uniaxially aligned polymer fibres. Materials Letters 2008;62:3370-3372.

14. Hur S, Kim WD. The electrospinning process and mechanical properties of nanofibre mats under vacuum conditions. Key Engineering Materials 2006;326-328:393-396.

15. Zhang YZ, Venugopal J, Huang ZM, Lim CT, Ramakrishna S. Characterization of the Surface Biocompatibility of the Electrospun PCL-Collagen Nanofibres Using Fibroblasts. Biomacromoecules 2005;6:2583-2589.

16. Arumuganathar S, Jayashinghe SN. Living Scaffolds (Specialized and Unspecialized) for Regenerative and Therapeutic Medicine. Biomacromolecules 2008;9(3):759-766.

17. Cui W, Li X, Zhou S, Weng J. Investigation on Process Parameters of Electrospinning System through Orthogonal Experimental Design. Journal of Applied Polymer Science 2007;103(5):3105-3112. 
18. Brown M, He F, Yeung LF. The First International Symposium on optimization and Systems Biology (OSB'07), Beijing, China, August 8-10, 2007, ORSC \& APORC pp. 259266.

19. Taguchi G. System of experimental design: engineering methods to optimize quality and minimize costs, White Plains, NY:UNIPUB, 1988.

20. Rekab K, Shaikh M. Statistical design of experiments with engineering applications, Chapman \& Hall/CRC, 2005.

21. Heikkilä P, Harlin A. Parameter Study of Electrospinning of Polyamide-6. European Polymer Journal 2008;44:3067-3079.

22. Rasband WS ImageJ, US National Institutes of Health, Bethesda, Maryland, USA (http://rsb.info.nih.gov/ij/), 1997-2005.

23. O'Connell B. Oval Profile Plot. Research Services Branch, National Institute of Mental Health, National Institute of Neurological Disorders and Stroke, http://rsbweb.nih.gov/ij/plugins/oval-profile.html

24. Ayres CE, Bowlin GL, Henderson SC et al. Modulation of anisotropy in electrospun tissue-engineering scaffolds: Analysis of fibre alignment by the fast Fourier transform Biomaterials 2006;27:5524-5534. 
JA Gómez-Tejedor et al., European Polymer Journal 47 (2011) 119-129

25. Ayres CE, Bowlin GL, Pizinger R, et al. Incremental changes in anisotropy induce incremental changes in the material properties of electrospun scaffolds. Acta Biomaterialia, $2007 ; 3(5): 651-661$.

26. Ayres $\mathrm{CE}$, Jha BS, Meredith $\mathrm{H}$, et al. Measuring fibre alignment in electrospun scaffolds: a user's guide to the 2D fast Fourier transform approach. J. Biomater. Sci. Polymer Edn. 2008;19(5):603-621.

27. Newton D, Mahajan R, Ayres C. Regulation of material properties in electrospun scaffolds: Role of cross-linking and fibre tertiary structure. Acta Biomaterialia 2009;5(1):518-529.

28. Reneker $\mathrm{DH}$, Yarin AL, Fong $\mathrm{H}$, Koombhongse S. Bending instability of electrically charged liquid jets of polymer solutions in electrospinning. J. Appl. Phys 2000;87(9):45314547.

29. Deitzel JM, Kleinmeyer J, Harris D, Beck Tan NC. The effect of processing variables on the morphology of electrospun nanofibres and textiles. Polymer 2001;42(1): 261-272.

30. Demir MM, Yilgor I, Yilgor E, Erman B. Electrospinning of polyurethane fibres. Polymer 2002;43(11):3303-3309.

31. Gupta P, Elkins C, Long TE, Wilkes GL. Electrospinning of linear homopolymers of poly(methyl methacrylate): exploring relationships between fibre formation, viscosity, molecular weight and concentration in a good solvent. Polymer 2005;46(13):4799-4810. 
JA Gómez-Tejedor et al., European Polymer Journal 47 (2011) 119-129

32. Zhao S, Wu $\mathrm{X}$, Wang $\mathrm{L}$, Huang $\mathrm{Y}$. Electrospinning of ethyl-cyanoethyl cellulose/tetrahydrofuran solutions. J. Appl. Polym. Sci 2004;91(1):242-246.

33. Megelski S, Stephens JS, Chase DB, Rabolt JF. Micro- and nanostructured surface morphology on electrospun polymer fibres. Macomolecules 2002;35(22):8456-8466.

34. Gao K, Hu XG, Dai CS, Yi T. Crystal structures of electrospun PVDF membranes and its separator application for rechargeable lithium metal cells. Materials Science \& Engineering B 2006;131:100-105.

35. Katti DS, Robinson KW, Ko FK, Laurencin CT. Bioresorbable nanofibre-based systems for wound healing and drug delivery: Optimization of fabrication parameters. J. Biomed. Mat. Res B: Appl. Biomat. 2004;70B(2):286-296.

36. Casper CL, Stephens JS, Tassi NG, Chase DB, Rabolt JF. Controlling surface morphology of electrospun polystyrene fibres: Effect of humidity and molecular weight in the electrospinning process. Macromolecules 2004;37(2):573- 578.

37. Fennessey SF, Farris RJ. Fabrication of aligned and molecularly oriented electrospun polyacrylonitrile nanofibres and the mechanical behavior of their twisted yarns. Polymer $2004 ; 45(12): 4217-4225$.

38. Mauck RL, Baker BM, Nerurkar NL, et al. Engineering on the Straight and Narrow: The Mechanics of Nanofibrous Assemblies for Fibre-Reinforced Tissue Regeneration. Tissue Engineering: Part B. 2009;15(2)171-193. 
JA Gómez-Tejedor et al., European Polymer Journal 47 (2011) 119-129

39. Garcia AJ. Get a grip: integrins in cell-biomaterial interactions. Biomaterials $2005 ; 26(36) 7525-7529$.

40. Vogel V, Baneyx G. The tissue engineering puzzle: A molecular perspective. Annu. Rev. Biomed Eng 2003;5:441-463.

41. Kazmers NH, Ma SA, Yoshida T, Stern PH. Rho GTPase signaling and PTH 3-34, but not PTH 1-34, maintain the actin cytoskeleton and antagonize bisphosphonate effects in mouse osteoblastic MC3T3-E1 cells. Bone 2009;45(1):52-60.

42. Gerecht S, Bettinger CJ, Zhang Z, et al. The effect of actin disrupting agents on contact guidance of human embryonic stem cells. Biomaterials 2007;28(28) 4068-4077.

43. Gugutkov D, Gonzalez-Garcia C, Hernandez JCR, et al. Biological Activity of the Substrate-Induced Fibronectin Network: Insight into the Third Dimension through Electrospun Fibres. Langmuir 2009;25(18):10893-10900.

44. Wray LS, Orwin EJ. Recreating the Microenvironment of the Native Cornea for Tissue Engineering Applications. Tissue Engineering: Part A 2009;15(7):1463-1472.

45. Veleva AN, Heath DE, Johnson JK, et al. Interactions between endothelial cells and electrospun methacrylic terpolymer fibres for engineered vascular replacements. J Biomed Mater Res 2009;91A(4):1131-1139. 